\title{
Gastric inhibitory polypeptide links overnutrition to obesity
}

A Ballinger

A gut derived peptide, gastric inhibitory polypeptide, directly links overnutrition to obesity and may be a potential target for antiobesity drugs

$\mathrm{O}$ besity and diabetes are two of the most prevalent health conditions in industrial nations. Recent studies suggest that a gut derived peptide, gastric inhibitory polypeptide (GIP), may be involved in the pathogenesis of type 2 diabetes and obesity induced by overnutrition. ${ }^{12}$ The "thrifty genotype" hypothesis suggests that those who are prone to obesity have been favoured by natural selection in the past because they possess genes that promote the efficient storage of ingested food as body fat for use in periods of undernutrition. However, with the sedentary lifestyle and year round plentiful food supply of modern society, the tendency is to accumulate fat. Miyawaki et al have shown that GIP directly links overnutrition to obesity and may be a potential target for antiobesity drugs. ${ }^{2}$

GIP was initially discovered and named for its gastric inhibitory properties. In 1886, Ewald and Boas showed that olive oil mixed with a meal inhibited both gastric emptying and acid secretion. In 1930 Kosaka and Lim proposed that this mixture liberated a chemical from the small intestine and went on to show that gastric acid secretion and gastric emptying could be inhibited by intravenously infused extracts of intestinal mucosa. ${ }^{3}$ They named the chemical "enterogastrone". Later, this factor was isolated and found to be localised to the duodenum and jejunum in specific endocrine cells named K-cells. ${ }^{4-6}$ Based on its effects the name "gastric inhibitory polypeptide" was proposed by Brown and Dryburgh in 1971..$^{7}$ Almost 40 years ago it was shown that there is a much greater insulin response and a smaller increase in blood glucose levels after an oral glucose load than after intravenous administration of equivalent amounts of glucose. ${ }^{89}$ The hormonal factor(s) thus implicated as transmitters of signals from the gut to the pancreatic $\beta$ cells were referred to as incretins and thought to be crucial in controlling postprandial insulin release. GIP is one of the incretins. It is released from the duodenum and jejunum in response to ingestion of a meal containing glucose or fat and potentiates glucose induced insulin secretion, so GIP is also referred to as glucose dependent insulinotropic poly-

Miyawaki K, Yamada Y, Ban N, et al. Inhibition of gastric inhibitory polypeptide signaling prevents obesity. Nat Med 2002;8:738-42.

Secretion of gastric inhibitory polypeptide (GIP), a duodenal hormone, is primarily induced by absorption of ingested fat. Here we describe a novel pathway of obesity promotion via GIP. Wild-type mice fed a high-fat diet exhibited both hypersecretion of GIP and extreme visceral and subcutaneous fat deposition with insulin resistance. In contrast, mice lacking the GIP receptor (Gipr(-/-)) fed a high-fat diet were clearly protected from both the obesity and the insulin resistance. Moreover, doublehomozygous mice (Gipr(-/-), Lep(ob)/Lep(ob)) generated by crossbreeding Gipr(-/-) and obese ob/ob (Lep(ob)/Lep(ob)) mice gained less weight and had lower adiposity than Lep(ob)/Lep(ob) mice. The Gipr(-/-) mice had a lower respiratory quotient and used fat as the preferred energy substrate, and were thus resistant to obesity. Therefore, GIP directly links overnutrition to obesity and it is a potential target for anti-obesity drugs.

peptide. ${ }^{10}{ }^{11}$ It has since also been shown that under physiological conditions in humans, GIP has a negligible effect on gastric acid secretion. ${ }^{12}$ The important role of GIP as an incretin hormone is demonstrated in GIP receptor knockout mice who show normal glucose tolerance after intraperitoneal administration of glucose and glucose intolerance accompanied by impaired insulin secretion after oral administration of glucose. ${ }^{13}$ The physiological role of GIP in the fasting state seems to be less important: fasting blood glucose and plasma insulin concentrations are the same in GIP receptor knockout and wild-type mice. ${ }^{13}$

In the present study, mice fed a high fat diet for 43 weeks demonstrated a 35\% increase in body weight compared with mice fed a control diet. This was associated with accumulation of fat in visceral and subcutaneous fat and in the liver. In contrast, weight gain and triglyceride synthesis induced by a high fat diet were prevented in mice lacking the GIP receptor. Fat accumulation on a control diet was similar in wild-type and receptor knockout mice. Thus interruption of the GIP signalling pathway prevented high fat diet induced obesity. Mice with a mutation in the leptin gene (ob/ob) have hyperphagia and are grossly obese. Absence of the GIP receptor in these mice results in reduced body weight indicating that the effects of GIP are independent of leptin.

Resistance to obesity of GIP receptor knockout mice is due to an inability to store fat in adipocytes and a higher energy expenditure. Food intake and excretion (in urine and faeces) of glucose and fat were similar in GIP receptor knockout and wild-type mice fed a high fat diet. GIP receptor knockout mice exhibited a significant reduction in respiratory quotient during the light phase but no changes in oxygen consumption compared with wild-type, indicating that the fat in receptor knockout mice was utilised as energy substrate and was not efficiently accumulated into adipocytes. The energy parameters only differed in the light phase when mice have low spontaneous motor activity indicating that the absence of GIP receptor primarily affects basal metabolism. The association of obesity with type 2 diabetes has been recognised for years. Obesity acts at least in part by inducing resistance to insulin mediated peripheral glucose uptake, which is an important component of type 2 diabetes. In this study the investigators showed that inhibition of GIP signalling prevented insulin resistance as well as obesity induced by a high fat diet. After subcutaneous administration of insulin, wild-type mice fed a high fat diet had higher nadir levels of blood glucose and then a more rapid increase in blood glucose compared with controls In contrast, GIP receptor knockout mice remained as sensitive to insulin as wildtype mice fed a control diet.

The GIP receptor is a seven transmembrane $G$ protein coupled receptor belonging to the secretin/vasoactive intestinal 
polypeptide family of receptors. It is expressed in various tissues including pancreatic islets, stomach, brain, and adipose tissue. GIP has a direct effect on adipocytes and has been shown to dose dependently stimulate lipoprotein lipase activity, fatty acid synthesis, and fatty acid incorporation into adipose tissue. ${ }^{214}$ Acyl CoA:diacylglycerol transferase 1 (Dgatl) catalyses the final step of triglyceride synthesis and mice deficient in this enzyme are resistant to obesity. Expression of Dgat l was significantly reduced in adipocytes from GIP receptor knockout mice compared with controls and the authors suggest that loss of peripheral GIP actions in GIP receptor knockout mice may contribute to the increased fat oxidation in these mice. $^{2}$

The authors propose a model for overnutrition in which excessive fat intake leads to hypersecretion of GIP, increased nutrient uptake into fat cells resulting in obesity, and in turn insulin resistance and hyperinsulinaemia. Although GIP receptor knockout mice are insulin sensitive they are glucose intolerant after oral glucose loading. ${ }^{13}$ Therefore, inhibition of GIP signalling to treat obesity may carry the price of impaired glucose tolerance or possibly frank diabetes.

Gut 2003;52:319-320

\section{Author's affiliation}

A Ballinger, Digestive Disease Research Centre, St Bartholomew's and the Royal London, Turner Street, London, UK a.b.ballinger@qmul.ac.uk

\section{REFERENCES}

1 Meier JJ, Mauck MA, Schmidt WE, et al, Gastric inhibitory polypeptide: the neglected incretin revisited. Reg Pept 2002;107:1-13.

2 Miyawaki K, Yamada Y, Ban N, et al Inhibition of gastric inhibitory polypeptide signaling prevents obesity. Nat Med 2002:8:738-42.

3 Kosaka T, Lim RKS. Demonstration of the humoral agent in fat inhibition on gastric secretion. Proc Soc Exp Biol Med 1930;27:890-1.

4 Brown JC, Mutt V, Pederson PRA. Further purification of a polypeptide demonstrating enterogastrone activity. I Physiol 1970:209:57-64.

5 Polak JM, Bloom SR, Kuzio M, et al, Cellular localisation of gastric inhibitory polypeptide in the duodenum and jejunum. Gut 1973;14:284-8.

6 Buffa B, Polak JM, Pearse AGE, et al. Identification of the intestinal cell storing gastric inhibitory polypeptide. Histochemistry 1975;43:249-55.

7 Brown JC, Dryburgh JR. A gastric inhibitory polypeptide II. The complete amino acid sequence. Can J Biochem 1971;49:867-72.
8 Elrick H, Stimmler L, Hlad CJ, et al, Plasma insulin response to oral and intravenous glucose administration. J Clin Endocrinol Metab 1964;24: 1076-82.

9 Mclntyre N, Holdsworth CD, Turner DS. Intestinal factors in the control of insulin secretion. J Clin Endocrinol 1965:25:1317-24.

10 Pederson RA, Schubert HE, Brown JC. Gastric inhibitory polypeptide. Its physiologic release and insulinotropic action in the dog. Diabetes 1975:24:1050-6.

11 Brown JC, Pederson RA. GI hormones and insulin secretion. Endocrinology. Proc Int Congr Endocrinol, $5^{\text {th }} 1976 ; 2: 568-70$.

12 Nauck MA, Bartels E, Ørskov C, et al, Lack of effect of synthetic human gastric inhibitory polypeptide and glucagon-like peptide 1 (7-36 amide) infused at near- physiological concentrations on pentagastrin-stimulated gastric acid secretion in normal human subjects. Digestion 1992:52:214-21.

13 Miyawaki K, Yamada Y, Yano H, et al, Glucose intolerance caused by a defect in the entero-insular axis: a study in gastric inhibitory polypeptide receptor knockout mice. Proc Natl Acad Sci U S A 1999;96:14843-

14 Beck B, Max JP. Gastric inhibitory polypeptide enhancement of the insulin effect on fatty acid incorporation into adipose tissue in the rat. Regul Pept 1983;7:3-8.

15 Oben J, Morgan L, Fletcher J, et al Effect of the entero-pancreatic hormones, gastric inhibitory polypeptide and glucagon-like polypeptide-1 (7-36) amide, on fatty acid synthesis in explants of rat adipose tissue. $J$ Endocrinol 1991;130:267-72. 